\title{
Early-Stage Juvenile Fibromyalgia in a 12-Year-Old Girl
}

\author{
Yoshihiko Sakurai \\ Department of Pediatrics, Matsubara Tokushukai Hospital, Matsubara, Japan \\ Email: ysakurai-th@umin.ac.jp
}

Received 8 December 2015; accepted 27 December 2015; published 30 December 2015

Copyright (C) 2015 by author and Scientific Research Publishing Inc.

This work is licensed under the Creative Commons Attribution International License (CC BY). http://creativecommons.org/licenses/by/4.0/

(c) (i) Open Access

\begin{abstract}
Juvenile fibromyalgia (JFM) is often diagnosed at a later stage. Therefore, little is known about its early phase. A 12-year-old girl with persistent lumbago without fever consulted an orthopedist, but imaging studies showed no abnormalities and analgesics were ineffective. She therefore visited our pediatric clinic. On digital palpation, she had pain in 13 of the 18 tender point sites of fibromyalgia. The blood test results were unremarkable. A medical interview revealed character tendencies often seen in patients with JFM; she was serious-minded, uncompromising, and showed excessive concern for others. Furthermore, psychological stress for the approaching annual sports day might have built up. All factors considered, early-stage JFM was the probable diagnosis. The patient accepted the diagnosis and understood that the disease may be psychogenic. Getting through the sports day cured her symptoms. This case highlights the importance of initial care, including a detailed explanation, in those with JFM.
\end{abstract}

\section{Keywords}

Juvenile Fibromyalgia, Early Stage, Character Tendency, Psychological Stress, Initial Care

\section{Introduction}

Fibromyalgia (FM) is a common chronic disease characterized by the presence of multiple symptoms such as widespread, constant pain throughout the body, sleeping disturbances, abnormal exhaustion, and cognitive problems, without chronic inflammation and no organic disorder in the etiology [1]. Although this condition occurs more commonly in women between the ages of 20 and 50, it can also affect men, teenagers, and children. Juvenile FM (JFM) is frequently overlooked, and often a long time is required to reach a correct diagnosis. As symptoms of JFM tend to be prolonged and may not resolve for longer period than previously thought [2], it is desirable to diagnose JFM as early as possible. However, the detailed symptoms and course of JFM in the early phase remain relatively less known. We herein report the case of a 12-year-old girl with early-stage JFM, in 
whom successful participation in a school event led to rapid resolution of symptoms. Informed consent was obtained from the patient and her parents for publication of this case report.

\section{Case Presentation}

A 12-year-old girl visited the orthopedic outpatient clinic at our hospital with complaints of a 1-month history of lumbago. Physical examination and computed tomography (CT) imaging revealed no abnormal findings. The finger-to-floor distance (FFD) was $0 \mathrm{~cm}$. The prescribed topical ketoprofen patch was not effective. The 1-week administration of an analgesic (acetaminophen: $400 \mathrm{mg} /$ day) did not reduce her pain; however, she did not develop a fever during this period. Furthermore, as cervical pain appeared, the patient and her mother were both very anxious regarding the unexplained, prolonged pain.

The patient was the only daughter of her parents. The family history was negative for rheumatic, autoimmune, or metabolic bone diseases. The patient's medical history was also negative. However, her backache, for which she had consulted an orthopedist, had been intermittent for several months, while she had had no fever since she noticed the lumbago. Furthermore, her pain was not localized to the lower back but was widespread, occurring at several sites. On physical examination, digital palpation yielded that she had pain in 13 of the 18 tender point sites (Figure 1). Tenderness was also evident over both thighs and the lateral sides of both feet. The other physical findings and neurologic findings were unremarkable. A complete blood count (CBC) showed a white blood cell count of $6,100 / \mu \mathrm{L}$ (neutrophils $45.8 \%$, lymphocytes $48.9 \%$, monocytes $3.3 \%$, basophils $0.7 \%$, and eosinophils 1.3\%). The erythrocyte sedimentation rate was $5.5 \mathrm{~mm} / \mathrm{h}$ and C-reactive protein level was $0.01 \mathrm{mg} / \mathrm{dL}$. The aspartate aminotransferase and alanine transaminase levels were $27 \mathrm{IU} / \mathrm{mL}$ and $23 \mathrm{IU} / \mathrm{mL}$, respectively. Her immunoglobulin levels were within normal range (immunoglobulin (Ig)A $155 \mathrm{mg} / \mathrm{dL}$, IgG $1328 \mathrm{mg} / \mathrm{dL}$, and IgM $140 \mathrm{mg} / \mathrm{dL}$ ). Levels of complement proteins were also within normal range (C3 $103 \mathrm{mg} / \mathrm{dL}$, C4 $20.1 \mathrm{mg} / \mathrm{dL}$, and total complement activity (CH50) $41 \mathrm{U} / \mathrm{mL}$ ). The antinuclear antibody test was negative. Thus, organ dysfunction and inflammation were not evident. A history of present illness, medical history, physical findings, and laboratory findings ruled out the differential diagnoses of rheumatic, orthopedic, and neurologic diseases. When all these facts were considered, the early phase of JFM was suspected.

Through a medical interview, the patient's character and living environment were revealed. She usually slept late at night and sometimes had fearful dreams. Her mother said that she had been strict with the patient and thought that she had scolded the patient more often than other mothers with children of the same age would have done. The patient liked school, enjoyed her classes, and had many friends in school. She served as the class representative and often arbitrated quarrels between classmates, but would worry afterwards whether she had made the right decision. She was liable to take on problems by herself without discussing them with anyone. Her ho-

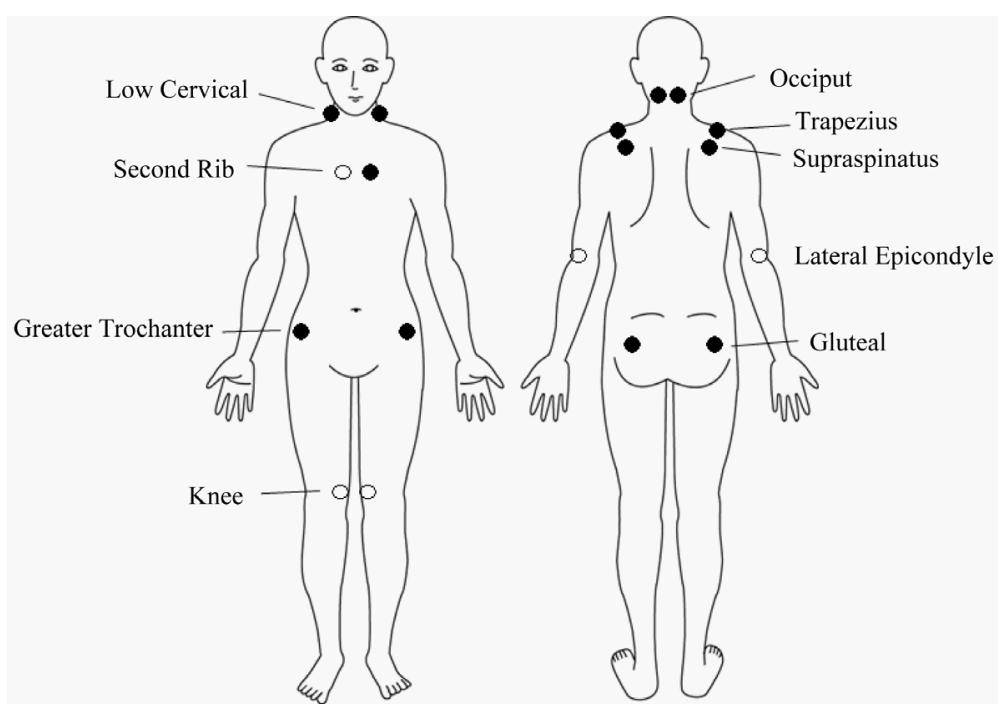

Figure 1. The 18 tender points associated with fibromyalgia. The closed circle indicates positive tender points, and the open circle represents points negative for tenderness. In this patient, 13 of 18 tender points were positive. 
meroom teacher would often advise her to express herself more freely.

The annual sports day at the patient's school was to be held within 2 months of her initial visit. At previous annual sports days, she had been selected for the relay team for 3 successive years. She was very chagrined when she had lost a relay race at the sports day held the previous year. She really wanted to win this upcoming race as it was going to be her last race in the elementary school phase and she had been practicing to run faster. Unfortunately, she found it difficult to continue practicing due to varying intensity of pain; moreover, she was afraid that the foot pain might occur in the race and prevent her from winning. The patient was also selected for an event where she would have to climb on top of a human pyramid, a kind of coordinated group gymnastic event. She was chosen to be at the top because she was relatively small in stature, but she was afraid of heights and had not shared this fact with anyone. The upcoming school event (the sports day), as well as her strained relationship with her mother, were likely the important psychological factors affecting her condition.

The patient's parents, especially her mother, were strongly advised to change the way they treated the patient and asked to avoid interacting with her very strictly. Analgesic medication was prescribed in a single dose as needed for severe pain. After the first visit, the pain persisted, but the intensity was slightly reduced. She continued attending school, and her everyday life was not seriously affected. The patient was able to climb to the top of the human pyramid in a rehearsal 1 day prior to the actual sports day; she repeated the successful feat on the sports day. She was also able to complete the relay race successfully.

The patient's systemic pain ceased completely immediately after the sports day. She stated that it did not matter whether she won or lost, and she did not share the outcome of the relay race with her attending doctor. When her parents asked her about the state of her health, she claimed that she no longer had any pain or tenderness. At present, she has been pain-free for more than 1 year.

\section{Discussion}

Chronic pain is not necessarily rare in children. About 30\% of children and adolescents have chronic pain that lasts for more than 3 months [3]-[5], which may include so-called growing pains and Osgood-Schlatter disease that develops in athletes. However, we seldom encounter a pediatric patient who has pain or tenderness at several points, which is specific to FM. In such cases, JFM as well as growing pains should be kept in mind in the differential diagnosis of chronic pains. Growing pains are more common in younger children than JFM and often appear in the night and resolve spontaneously [6], whereas JFM symptoms are chronic or last for months to years. Although the definitive diagnostic criteria of JFM are not yet established, several criteria have been proposed, in which the detection of tender points is of vital importance [7]-[10]. In our case, neither the American College of Rheumatology criteria [10] nor the Yokohama criteria [11] were fulfilled because it was uncertain that the patient had suffered from persistent widespread pain for more than 3 months, even though the patient had suffered from occasional back pain for more than a few months. Although she had mild sleep disturbance, the chronic fatigue and autonomic symptoms such as inappropriate sweating, cyanosis, and peripheral coldness that are reportedly observed in JFM were not evident. Furthermore, she had no symptoms of photophobia, irritable bowel syndrome, or an eating disorder. She did not refuse to attend school. We could not therefore confirm the diagnosis of JFM, but a probable early-stage JFM as oppressive pain was evident in 13 of the 18 points, and pain was not detected 1 inch away from the point of tenderness. A recent review describes that representative symptoms in JFM may not present at once in the early stages [2], which supports our notion.

JFM most frequently affects children at approximately 10 years of age (4th - 5th grade in elementary school) and predominantly female children [11]. The patient matched the age and sex criteria. In JFM, elevated emotional distress, especially elevated anxiety, is not uncommon [2]. We did not observe heightened levels of emotional distress but she showed character tendencies such as being serious-minded, uncompromising, and having excessive concern for others, which is reportedly observed in patients with JFM. She might have had some problems associated with pain, including a fraught mother-child relationship and stressful personal relationships in the classroom, which are considered causes and backgrounds of disease development [11]. With such a background, the patient's anxiety about the approaching sports day, especially the relay race and coordinated group gymnastic event might have triggered an exacerbation of JFM. Although the pain and tenderness were initially expected to be prolonged, both promptly disappeared after she completed the relay race with maximum efforts and the human pyramid with her team was successfully formed on the sports day. Patient's environment as well as psychological state may trigger onset and affect the medical condition. Parental and familial pain experiences 
are associated with patients' use of catastrophic thinking to cope with chronic pain [12]. Poor family functioning are evident in families of adolescents with JFM [13]. In our case, relatively healthy family functioning without parents' chronic pain might contribute to early disappearance of symptoms. Our case is likely to accord with previous literature, which describes that symptoms in some pediatric patients with JFM decrease or disappear only on reaching the correct diagnosis of JFM [14] or repeated medical interviews without prescribing any medications [15].

\section{Conclusion}

Our patient had both family and school problems such as a fraught mother-daughter relationship and personal relationship problems with her classmates based on the background of her character traits such as perfectionism, a strong sense of responsibility, tenacity, and a tendency to pay too much attention to other people [9]. In addition to these, she was unable to handle the pressure of the fast-approaching annual sports day. Considering these circumstances, she was likely to develop JFM. A probable diagnosis of JFM at the first visit and the explanation provided to the family that JFM is often associated with psychogenic factors relieved their anxiety. Furthermore, she overcame the challenges of the sports day, which provided relief of the symptoms in the short term. Our experience suggests that clinical suspicion of JFM and proper care, including a detailed explanation of the disease, are of critical importance in management of early-stage JFM.

\section{References}

[1] Hawkins, R.A. (2013) Fibromyalgia: A Clinical Update. The Journal of the American Osteopathic Association, 113, 680-689. http://jaoa.org/article.aspx?articleid=2094606 http://dx.doi.org/10.7556/jaoa.2013.034

[2] Kashikar-Zuck, S. and Ting, T.V. (2014) Juvenile Fibromyalgia: Current Status of Research and Future Developments. Nature Reviews Rheumatology, 10, 89-96. http://www.nature.com/nrrheum/journal/v10/n2/pdf/nrrheum.2013.177.pdf http://dx.doi.org/10.1038/nrrheum.2013.177

[3] Valente, A.M., Jain, R., Scheurer, M., Fowler, V.G.J., Corey, G.R., Bengur, A.R., Sanders, S. and Li, J.S. (2005) Frequency of Infective Endocarditis among Infants and Children with Staphylococcus aureus Bacteremia. Pediatrics, 115, e15-e19. http://pediatrics.aappublications.org/content/115/1/e15.long

[4] Fuss, S., Page, G. and Katz, J. (2011) Persistent Pain in a Community-Based Sample of Children and Adolescents. Pain Research \& Management, 16, 303-309. http://www.ncbi.nlm.nih.gov/pmc/articles/PMC3206778/

[5] King, S., Chambers, C.T., Huguet, A., MacNevin, R.C., McGrath, P.J., Parker, L. and MacDonald, A.J. (2011) The Epidemiology of Chronic Pain in Children and Adolescents Revisited: A Systematic Review. Pain, 152, 2729-2738. http://dx.doi.org/10.1016/j.pain.2011.07.016

[6] Uziel, Y. and Hashkes, P.J. (2007) Growing Pains in Children. Pediatric Rheumatology Online Journal, 5, 5. http://dx.doi.org/10.1186/1546-0096-5-5

[7] Yunus, M.B. and Masi, A.T. (1985) Juvenile Primary Fibromyalgia Syndrome. A Clinical Study of Thirty-Three Patients and Matched Normal Controls. Arthritis \& Rheumatology, 28, 138-145.

http://onlinelibrary.wiley.com/doi/10.1002/art.1780280205/pdf http://dx.doi.org/10.1002/art.1780280205

[8] Wolfe, F., Smythe, H.A., Yunus, M.B., Bennett, R.M., Bombardier, C., Goldenberg, D.L., Tugwell, P., Campbell, S.M., Abeles, M., Clark, P., et al. (1990) The American College of Rheumatology 1990 Criteria for the Classification of Fibromyalgia. Report of the Multicenter Criteria Committee. Arthritis \& Rheumatology, 33, 160-172. http://onlinelibrary.wiley.com/doi/10.1002/art.1780330203/pdf http://dx.doi.org/10.1002/art.1780330203

[9] Yokota, S. (2009) Juvenile Fibromyalgia. In: Nishioka, K., Ed., Guidance for Diagnosis and Management, Medical Review, Tokyo, 75-82.

[10] Wolfe, F., Clauw, D.J., Fitzcharles, M.A., Goldenberg, D.L., Katz, R.S., Mease, P., Russell, A.S., Russell, I.J., Winfield, J.B. and Yunus, M.B. (2010) The American College of Rheumatology Preliminary Diagnostic Criteria for Fibromyalgia and Measurement of Symptom Severity. Arthritis Care \& Research (Hoboken), 62, 600-610. http://onlinelibrary.wiley.com/doi/10.1002/acr.20140/full http://dx.doi.org/10.1002/acr.20140

[11] Yokota, S., Kikuchi, M. and Miyamae, T. (2013) Juvenile Fibromyalgia: Guidance for Management. Pediatrics International, 55, 403-409. http://onlinelibrary.wiley.com/doi/10.1111/ped.12155/full 
http://dx.doi.org/10.1111/ped.12155

[12] Schanberg, L.E., Anthony, K.K., Gil, K.M., Lefebvre, J.C., Kredich, D.W. and Macharoni, L.M. (2001) Family Pain History Predicts Child Health Status in Children with Chronic Rheumatic Disease. Pediatrics, 108, E47. http://pediatrics.aappublications.org/content/108/3/e47.long http://dx.doi.org/10.1542/peds.108.3.e47

[13] Kashikar-Zuck, S., Lynch, A.M., Slater, S., Graham, T.B., Swain, N.F. and Noll, R.B. (2008) Family Factors, Emotional Functioning, and Functional Impairment in Juvenile Fibromyalgia Syndrome. Arthritis \& Rheumatology, 59, 1392-1398. http://onlinelibrary.wiley.com/doi/10.1002/art.24099/full http://dx.doi.org/10.1002/art.24099

[14] Miyamae, T., Watanabe, Y. and Yokota, S. (2008) The Actual State and Clinical Features of Fibromyalgia in Our Country. The Journal of the Japan Pediatric Society, 112, 1769-1777.

[15] Yokota, S., Umebayashi, H., Miyamae, T., Imagawa, T. and Mori, M. (2007) Our Experience of 3 Cases with Childhood Fibromyalgia. The Journal of the Japan Pediatric Society, 111, 462-468. 